\title{
Flow Regime Identification in a Fluidized Bed Combustion Reactor
}

\author{
Rajan K. Thapa, Christoph Pfeifer and Britt M. Halvorsen
}

\begin{abstract}
A comprehensive 3D Computational Particle Fluid Dynamic (CPFD) model is prepared to study the gas-solid isothermal flow in a riser of a dual fluidized bed biomass gasification system. The fluidizing gas is air, and the particles are olivine, char, and their mixture. The isothermal temperature of the particle and fluid flow is maintained at $\mathbf{1 3 0 0}$ $\mathrm{K}$. Bubbling, turbulent and fast fluidization regimes in the reactor with their corresponding velocities are identified. The bed inventory emptying method is implemented to find the transport velocity. Average pressure drop and bed material influx and out-flux are monitored at a wide range of gas velocities to determine the stable flow regimes in the bed for solid transport. The fluidization properties of the bed of olivine particles differ significantly from the bed of the mixture of olivine particles and char particles. Effects of the bottom, primary and secondary air flows on the fluidization regime and particle transport rate have been investigated.
\end{abstract}

Index Terms - CPFD, fluidized bed, fluidization regimes.

\section{INTRODUCTION}

Various thermo-chemical processes are used to extract energy from biomass. Gasification is one of them. The application of dual fluidized bed steam gasification system has increased during the past two decades [1], [2]. The system consists of a dual fluidized bed reactor which is divided into two parts: gasification and combustion as shown in Figure 1. The gasification reactor or gasifier is a bubbling fluidized bed with high-temperature steam as fluidizing gas. In this reactor, biomass is mixed with hot bed materials and steam to produce a mixture of combustible gasses known as product gas. The major compositions of the product gas are methane, carbon monoxide, and hydrogen in addition to some carbon dioxide and water vapor [3-6]. The gasification reactions are endothermic and need external heat, which is supplied by the combustion reactor.

In the combustion reactor, bed materials are heated by burning residual char particles which are coming from the gasifier along with the bed materials. The combustion reactor is a circulating fluidized bed with air as a fluidizing gas. The air also provides necessary oxygen for the combustion process. Air is supplied to the reactor at three positions: one at the bottom part of the reactor and two others are along the height of the reactor, and they are called a bottom, primary and secondary air respectively. The bottom air is supplied to

Manuscript received March 1, 2016; revised May 25, 2016.

Rajan K. Thapa and Britt M. Halvorsen is with the University College of South East Norway, kjølnes ring 56, 3901, Porsgrunn, Norway (e-mail: rajan.k.thapa@hit.no,britt.moldestad@hit.no).

Christoph Pfeifer is with University of Natural Resources and Life Sciences, Gregor-Mendel-Strasse 33, 1180, Vienna Austria, Austria (e-mail: christoph.pfeifer@boku.ac.at). maintain bubbling fluidization regime at the lower part of the reactor whereas the primary and the secondary air transport the bed materials from the combustion reactor to the gasification reactor.

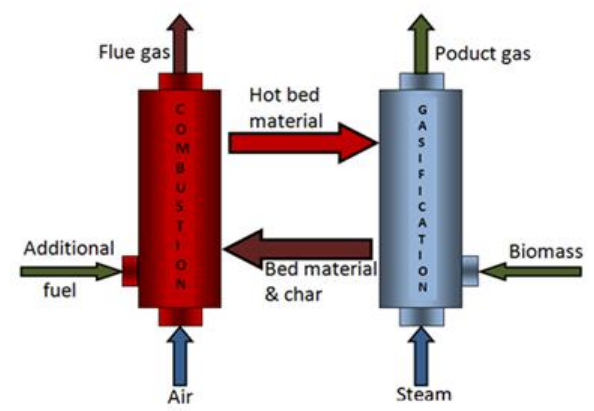

Fig. 1. Principle of dual fluidized bed gasification system.

The fluidization regime of the riser is complex because it maintains bubbling fluidization regime at the bottom part and fast fluidization regime at the higher part of the reactor. In some cases, the flow regime at the most top part of the reactor can be even pneumatic transport regime depending upon the feed rate of secondary air.

The two most important parameters of the system, bed material temperature, and its circulation rate are affected by the air flow and fluidization regime. In the combustion riser, the solid flux is usually high (about $120 \mathrm{~kg} /\left(\mathrm{m}^{2} \mathrm{~s}\right)$ ). This solid flux is maintained at steady state by fast fluidization or pneumatic conveying flow regimes [7]. The flow regime is dependent on particle size, density, and composition as well as fluid properties such as density and viscosity. Different flow regimes provide different gas-solid mixing and chemical reaction rates [8]. Understanding the flow regime in the reactor is a key factor for successful design, scaling, and optimization of the reactor.

The study of flow regime in a circulating fluidized bed has a long history with various proposed flow regime maps. Yerushalmi et al. have shown the transition between packed bed, bubbling bed, turbulent and fast fluidization regimes in the plot of bed voidage against superficial gas velocities [9]. Flow regime maps of gas-solid flow are also developed plotting gas velocity against the solid flux [10]. Takeuchi et al. performed experimental measurements to define the boundaries of fast fluidization [11]. Hirama et al. extended the flow diagram to transition from high velocity to low-velocity fluidization regimes [12]. $\mathrm{Bi}$ and Grace proposed unified flow regime diagram based on the experimental findings. They have shown the relationship between flow regimes for both gas-solid fluidization and the co-current upward transport [13]-[15]. All of those flow 
regime maps are proposed for the beds of similar particles and cannot be implemented for the combustion reactor in the gasification system due to the following reasons. They do not represent beds with a binary mixture which is the case in this work; particle size distribution is not considered, and experiments are carried out at ambient conditions without taking into account high-temperature conditions. These factors significantly affect the flow properties and change the fluidization regime. For example, the wider particle size distribution gives rise to smaller voids and earlier transition from bubbling to turbulent regime [16]. When particles with a larger size and lower density are mixed with the particles of smaller size and higher densities, the minimum fluidization velocity changes [17]. Change in minimum fluidization velocity effects in the transport velocity and fast fluidization velocity. High-temperature gasses have lower density and higher viscosity. Change in density and viscosity changes flow behavior in fluidized bed.

The combustion reactor operates at high temperature. The particle temperature is about $950^{\circ} \mathrm{C}$ and fluid temperature is even higher [18]. Understanding of flow regime requires measurements of pressure, temperature and solid volume fractions and solid flux. The measurements at high temperature need strong safety consideration. In a particular case, the measurements of solid volume fraction and solid flux are very difficult in the hot reactors. It may be the reason why the experimental investigations of the flow behavior of high temperature operated circulating fluidized beds are rare in publications [19]. Some authors scaled down the reactor to work at the ambient conditions [20], [21]. They managed to overcome the high-temperature problem. However, the precise scaling requires the particles with a density more than $12000 \mathrm{~kg} / \mathrm{m}^{3}$, which are not easily found in the market. They had to rely on the available bronze particles of density about $9000 \mathrm{~kg} / \mathrm{m}^{3}$. The computational study of the flow regime helps to overcome both of the problems. It is possible to solve high-temperature flow with a wide range of particle size and gas properties using Computational Particle Fluid Dynamic (CPFD) models.

A 3D CPFD model is used to study the high-temperature gas-particle flow regimes in a fluidized bed combustion reactor. The reactor in the $8 \mathrm{MW}$ biomass gasification plant in Güssing, Austria is a reference for the current model. Particles and gas properties as well as the flow and geometric parameters are based on the plant data [22], [23]. The model has two objectives: identification of parameters affecting the flow regime with special focus in more sensitive transitions and to investigate the effect of primary and secondary air feed rate on flow regimes and particle transport process.

\section{DETERMINATION OF FlUIDIZATION VELOCITIES}

The flow regimes in a fluidized bed reactor are packed bed, particulate fluidization, bubbling fluidization, slugging, turbulent fluidization, fast fluidization, and pneumatic transport which occur at increasing gas velocities. A range of fluidization velocities specifies every regime of the fluidization. Air is fed at three positions in the combustion reactor which are known as the bottom, primary and secondary air. Circulating fluidized beds of high solid flux (about $120 \mathrm{~kg} /\left(\mathrm{m}^{2} \mathrm{~s}\right)$ ) work at fast fluidization regime.
However, the lower part of the combustion reactor in this work has to be maintained in bubbling fluidization regime. It is necessary to keep low air velocity (bubbling fluidization regime) at the bottom for preventing leakage of air to the 31 gasification part through connecting chute. Leakage of the air from combustion reactor to gasification reactor is undesirable because it dilutes the product gas reducing the calorific value.

A detailed study of the fluidization velocities from minimum fluidization to pneumatic transport is necessary to establish a big picture of flow regimes in the reactor. The velocities are calculated using theoretical correlations. The theoretical calculations give an approximation for the CPFD model. Minimum fluidization velocity of the particles is calculated using Equation 1. The equation is derived from Ergun equation with gravity- equals - drag balance with Wen and Yu simplification [24]-[26].

$$
u_{m f}=\frac{\left(\varphi \cdot d_{p}^{2}\right)\left(\rho_{p}-\rho_{g}\right) \cdot g}{1650 \mu}
$$

For Geldart B particles, the bubbling velocity starts with the minimum fluidization velocity. The bed has an aspect (H/D) ratio about 22, which is comparatively high. Slugging is possible in bed with an aspect ratio greater than 2 . Slugging produces a large pressure fluctuation in the bed resulting reduced gas-solid mixing which is undesirable. However, for the bed with large diameter $(0.66 \mathrm{~m})$ with comparatively small particles of Geldart group B, it is more likely to transfer the fluidization regime from bubbling to turbulent [27]. A plot of pressure drop against the superficial gas velocity gives two distinct velocities $U_{c}$ and $U_{k}$ in turbulent regime. $U_{c}$ corresponds to the bed operating condition when the bubble or slug reaches their maximum resulting significant pressure drop [28]. Continuous increase in the gas velocity starts to break up bubbles resulting in smaller pressure fluctuation which makes the flow steady. The velocity in this state is $U_{k}$. The velocities are calculated using Equations 2 and 3 proposed by Horio [29]. Steady pressure fluctuation maintains the constant rate of particle transport which is essential for the uniform heat transfer process in the gasification reactor.

$$
\begin{aligned}
& (\operatorname{Re})_{c}=\frac{d_{p} \rho_{g} U_{c}}{\mu}=0.936 A r^{0.472} \\
& (\operatorname{Re})_{k}=\frac{d_{p} \rho_{g} U_{c}}{\mu}=1.46 A r^{0.472}
\end{aligned}
$$

Further increase in the gas velocity leads flow to fast fluidization. The velocity in this state is known as transport velocity. The velocity is calculated by Equation 4 [15].

$$
U_{t r}=1.53 A r^{0.5} \text { for } 2<A r<4.10^{-5}
$$

The final transition is from fast fluidization to pneumatic transport. The transition velocity from fast fluidization to pneumatic transfer is known as chocking velocity.

The bubbling bed is characterized by the solid concentration about $0.45-0.25$ whereas the turbulent bed is characterized by the solid concentration from 0.25 and lower [30]. The pneumatic transport regime occurs at the solid 
volume fraction less than $1 \%$. Fast fluidization regime occurs when the solid volume fraction is $5-15 \%$ at the lower part and $1-5 \%$ at the upper part of the bed [31]. The theoretical gas velocities of the olivine and char particles are calculated and used as a starting value for the model simulation. At the same time, the theoretical results are compared with the computational prediction of the model.

\section{MATHEMATICAL MODEL}

In this work, a Computational Particle Fluid Dynamic (CPFD) model have been implemented to simulate the gas-solid flow with heat transfer and chemical reactions. Commercial CPFD software Barracuda VR 15 is used for simulation. The CPFD numerical methodology incorporates multi-phase-particle-in-cell (MP-PIC) method [32]. The gas phase is solved using Eulerian grid, and the particles are modeled as Lagrangian computational particles. Gas and particle momentum equations are solved in three dimensions. The fluid is described by the Navier-Stokes equation with strong coupling to the discrete particles. The particle momentum follows the MP-PIC description which is a Lagrangian description of particle motions described by ordinary differential equations with coupling with the fluid [33].

In the CPFD numerical method, actual particles are grouped into computational particles, each containing a number of particles with identical densities, volume, and velocities located at a particular position. The computational particle is a numerical approximation similar to the numerical control volume where a spatial region has a single property for the fluid. With these computational particles, large commercial systems containing billions of particles can be simulated using millions of computational particles.

\section{GOVERNING EQUATIONS}

The volume averaged fluid mass, and momentum equations are:

$$
\frac{\partial\left(\varepsilon_{g} \rho_{g} \mathbf{u}_{g}\right)}{\partial t}+\nabla\left(\varepsilon_{g} \rho_{g} \mathbf{u}_{g} \mathbf{u}_{g}\right)=\nabla p-\mathbf{F}+\varepsilon_{g} \rho_{g} \mathbf{g}
$$

where $\varepsilon_{g}, \rho_{g}$ and $\mathbf{u}_{g}$ are gas volume fraction, density and velocity respectively, $\mathrm{p}$ is gas pressure, $\mathbf{g}$ is the acceleration due to gravity and $\tau_{g}$ is stress tensor which can be expressed in index notation as:

$$
\tau_{g, i j}=\mu\left(\frac{\partial u_{i}}{\partial x_{j}}+\frac{\partial u_{j}}{\partial x_{i}}\right)-\frac{2}{3} \mu \delta_{i j} \frac{\partial u_{k}}{\partial x_{k}}
$$

where $\mu$ is shear viscosity. The shear viscosity is the sum of laminar shear viscosity and turbulence viscosity based on the Smagorinsky turbulence model. In the model, large eddies are directly calculated. The unresolved sub-grid turbulence is modeled by using eddy viscosity. The turbulence viscosity is given as:

$$
\mu_{t}=C \rho_{g} \Delta^{2} \sqrt{\left(\frac{\partial u_{i}}{\partial x_{j}}+\frac{\partial u_{j}}{\partial x_{i}}\right)^{2}}
$$

where $C$ is sub-grid eddy coefficient and known as Smagorinsky coefficient.

MP-PIC method calculates the particle phase dynamics using the particle distribution function (PDF), $f_{p}$. A transport equation is solved for the PDF. The transport equation for $f_{p}$ is given by [34] is:

$$
\frac{d_{f}}{d t}+\frac{\partial\left(f_{p} u_{p}\right)}{d x}+\frac{\partial\left(f_{p} A_{p}\right)}{d u}=\frac{f_{D}-f}{\tau_{D}}
$$

where $u_{p}$ is particle velocity, $f_{D}$ is the particle distribution function for the local mass averaged particle velocity and $\tau_{D}$ is the collision damping time. $A_{p}$ is the particle acceleration which is given by:

$$
A_{p}=\frac{\partial u_{p}}{d t}=D_{p}\left(u_{g}-u_{p}\right)-\frac{1}{\rho_{p}} \nabla p_{g}+g-\frac{1}{\varepsilon_{p} \rho_{p}} \nabla \tau_{p}+g+F_{p}
$$

In the equation above, $\varepsilon_{p}$ is particle volume fraction, $\rho_{p}$ is particle density, $\rho_{p}$ is gas pressure, $\tau_{p}$ is contact normal stress. More details about the $\tau_{p}$ can be found in (O'Rourke and Snider, 2010). $F_{p}$ is the particle friction per unit mass and $D_{p}$ is the drag function. The Wen-Yu drag model has been implemented in this work [35].

$$
D_{p}=C_{D} \frac{3}{8} \frac{\rho_{g}}{\rho_{p}} \frac{\left|u_{g}-u_{p}\right| \varepsilon_{g}^{-2.65}}{r_{p}}
$$

where

$$
\begin{gathered}
D_{p}=C_{D}\left\{\begin{array}{l}
\frac{24}{\operatorname{Re}}\left(1+0.15 \mathrm{Re}^{0.678}\right) \mathrm{Re}<1000 \\
0.44 \quad \operatorname{Re} \geq 1000
\end{array}\right. \\
\operatorname{Re}=\rho_{g} \frac{\left|u_{g}-u_{p}\right| r_{p}}{\mu_{g}} \text { and } r_{p}=\left(\frac{m}{\frac{4}{3} \pi \rho_{p}}\right)^{1 / 3}
\end{gathered}
$$

\section{MOdEL SETUP AND PARAMETERS}

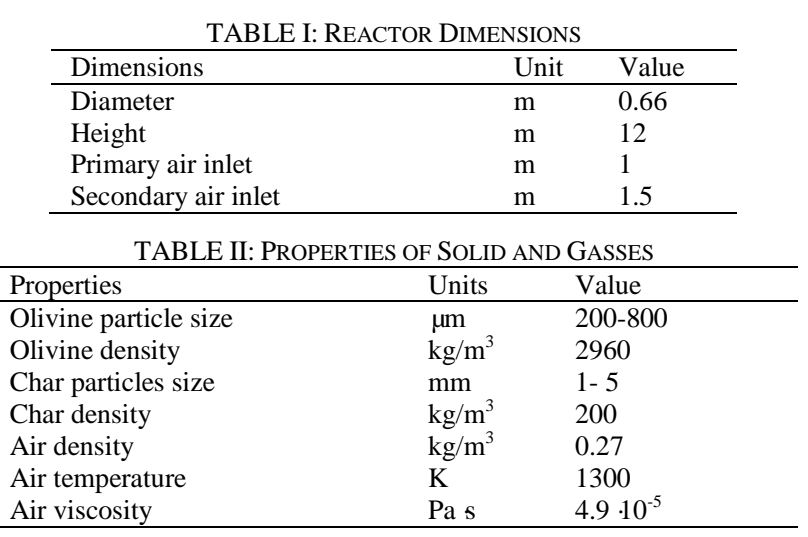

The dimensions of the reactor are the same as the combustion reactor in the biomass gasification plant in 
Güssing, Austria. The basic dimensions are presented in Table I.

The circulation system such as cyclone separator and down-flow pipes are not involved. The aim is to study the flow only in the riser. The properties of gas and solid particles used in the model are presented in Table II.

\section{RESULTS AND DISCUSSIONS}

The bed of three different particles olivine, char, and a mixture of olivine and char were fluidized at increasing superficial gas velocities. Pressure drops across the height of the bed are monitored and plotted against the wide range of the superficial gas velocities. The plot is presented in Figure 2. The minimum fluidization velocities of char and olivine particles have about the same value of $0.06 \mathrm{~m} / \mathrm{s}$. Theoretical calculation of the corresponding velocities are 0.053 and $0.058 \mathrm{~m} / \mathrm{s}$ respectively. The reason of the deviations between the values is due the particle size distributions which are not possible to consider in theoretical calculations. When the olivine particles are mixed with the char particles, the minimum fluidization velocity increases to $0.34 \mathrm{~m} / \mathrm{s}$. The increase occurs when mixing only $1 \mathrm{vol} \%$ of char particles which is the case in the biomass gasification plant in Güssing.

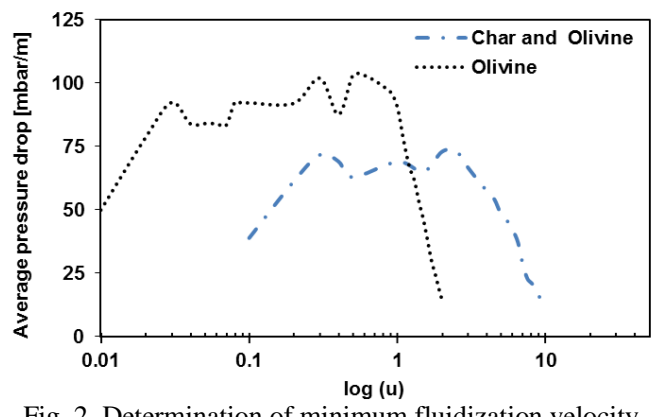

Fig. 2. Determination of minimum fluidization velocity.

The particles involved in this binary mixture have a different size as well as density. The char particles have a very lower density $\left(200 \mathrm{~kg} / \mathrm{m}^{3}\right)$ in comparison to the olivine particles $\left(2960 \mathrm{~kg} / \mathrm{m}^{3}\right)$. The char particles have a large range of size distribution $(0.5 \mathrm{~mm}-5 \mathrm{~mm})$ whereas the olivine particles have size distribution $200 \mu \mathrm{m}$ to $800 \mu \mathrm{m}$.

It is believed that the bulk density and voidage are the main factors defining the quality of fluidization. The minimum fluidization velocity decreases with increasing temperature in the bed. Minimum fluidization velocity of particles with a wide range of size distribution varies with the fraction of coarse particles due to different inter-particle forces. When coarse particles are added in a bed of comparatively fine particles, the voidage of the bed is increased significantly. The solid volume fractions of all particles (olivine, char and the mixture of olivine and char) at minimum fluidization conditions are monitored, and the corresponding void fractions are calculated. The void fraction of olivine, char and the mixture of olivine and char are $0.44,0.45$ and 0.52 respectively. The highest value of void fraction in the mixture is the primary reason for large increase in minimum fluidization velocity. This result reveals that the study of flow regimes of the combustion reactor without considering the presence of coarse char particles gives a significant error.

The significant difference of minimum fluidization velocities between the bed of olivine particle and the bed of the mixture of olivine and char particles indicates that there should be the corresponding difference in transport velocities as well. A simple method was used to determine the transport velocities in which the bed inventory emptying time was monitored at different gas velocities as shown in Figure 3. At the gas velocity lower than $12 \mathrm{~m} / \mathrm{s}$ the bed inventory emptying time is large. The time required to empty the mixture particles is 194 and 120 seconds at the superficial gas velocities of 10 and $11 \mathrm{~m} / \mathrm{s}$ respectively (Fig. 3a).
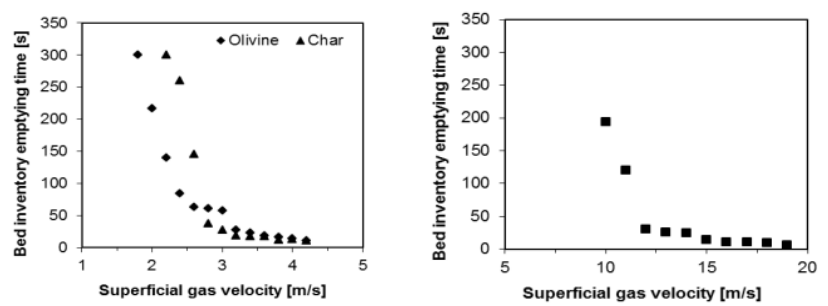

Fig. 3. Determination of transport velocity (a) mixture of char and olivine (b) olivine and char particles separately.

When the gas velocity is increased to $12 \mathrm{~m} / \mathrm{s}$, the particle emptying time is suddenly decreased to 30 seconds and does not change significantly with the increasing gas velocity. It is the beginning of fast fluidization regime of the bed, and the velocity is the transport velocity. The transport velocities for the bed of olivine and char particles give lower values of 2.6 $\mathrm{m} / \mathrm{s}$ and $2.8 \mathrm{~m} / \mathrm{s}$ respectively (Figure $3 \mathrm{~b}$ ). The transport velocity is about 40 times the minimum fluidization velocity for all the particles showing that the transport velocity is dependent on the minimum fluidization velocity of the particles in the bed.

Further investigations were continued only for the bed with the mixture of char and olivine particles which is the case in the combustion reactor of the dual fluidized bed gasification system. A series of simulations were run to investigate average pressure drop across the bed for a constant solid influx at increasing superficial gas velocity. Individual simulations were run for each of the solid feed rates of $5,10, \ldots, 55 \mathrm{~kg} / \mathrm{s}$. The average pressure drops on the bed were monitored at increasing dimensionless gas velocities from $6 \mathrm{u}_{\mathrm{mf}}$ to $58 \mathrm{u}_{\mathrm{mf}}$. The dimensionless gas velocity is the ratio of superficial gas velocity to the minimum fluidization velocity.

The average pressure drop across the height depends on the solid influx (Fig. 4). The average pressure drop increases with increasing solid influx and also varies with increasing gas velocity up to particular value. First, the average pressure drop increases continuously with increasing gas velocity and then gradually decreases after attaining the highest value.

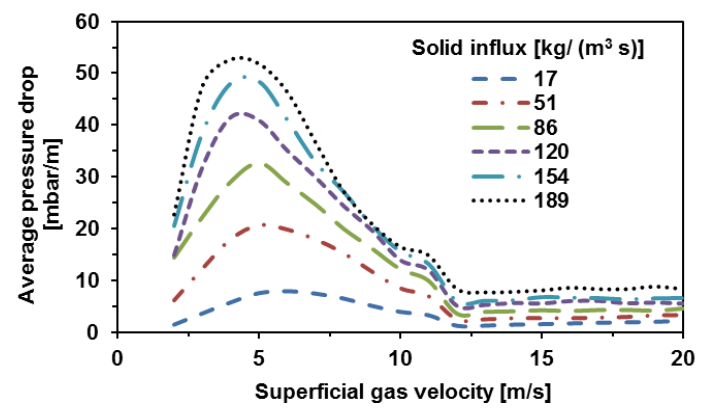

Fig. 4. Average pressure drops vs. gas velocity. 
The variation in average pressure drop continues up to the gas velocity of about $35 \mathrm{u}_{\mathrm{mf}}$ and then remains constant at the higher gas velocities. The velocity in this case is equal to the transport velocity. Above this gas velocity, there is no variation in pressure drop. The pressure drop remains constant for a given solid influx. The transport velocity is independent of solid influx.

The influence of the average pressure drop variation on the solid out-flux was also studied by monitoring the solid out-flux at the same solid influx and varying gas velocities which are presented in Fig. 5.

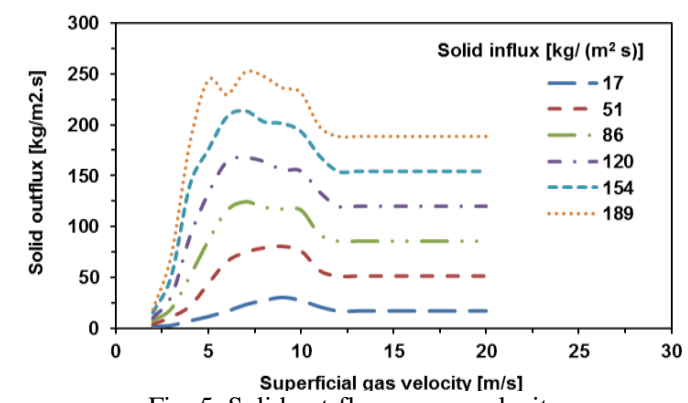

Fig. 5. Solid out-flux vs. gas velocity.

The large variations in the average pressure drop are linked to the fluidization regime change in the bed from bubbling fluidization to turbulent. The significant variation in the average pressure drop causes a large variation in solid out-fluxes within that range of gas velocity. The particle out-flux is greater than influx at the range of dimensionless superficial gas velocities form 15 to 35 . This range of gas velocity should be avoided for a smooth and steady operation of the riser. The major function of the riser is not only supply bed material but also maintain its constant feed rate. Even the upper part of the riser has fast fluidization regime; the lower part should be in the bubbling fluidization due to the process requirements. Therefore, particular attention should be given to avoid this velocity range in the combustion reactor.

In Fig. 6, contours of particle volume fractions at increasing air velocities are presented. The particles here are the mixture of olivine and char. The contours are a snapshot of the particle volume fraction. At the dimensionless superficial air velocity of 10 the particle volume fraction at the bottom of the reactor is significantly higher than the upper part. At the outlet, the volume fraction is about $0.05 \%$ indicating the very low outflow rate of the particles. With increasing air velocity, the volume fraction at the bottom part decreases while at the upper part it increases.

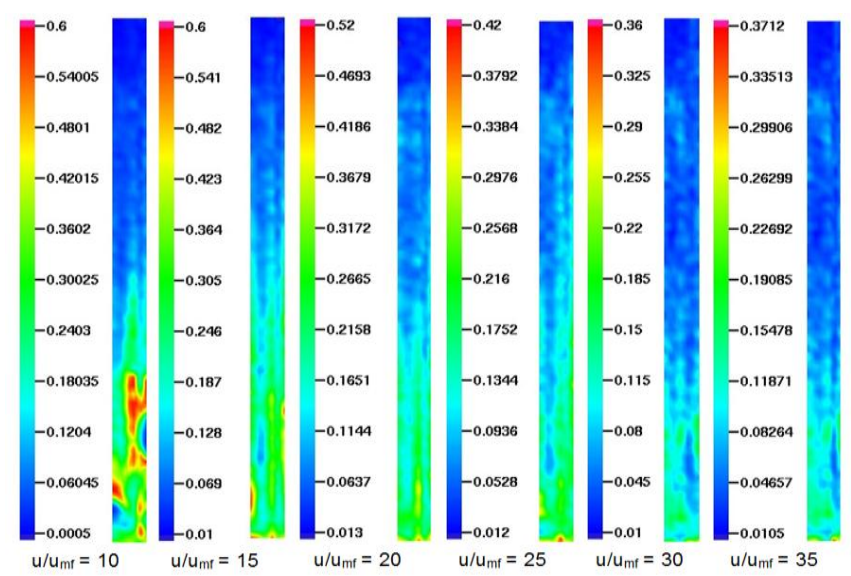

Fig. 6. Contours of solid volume fraction vs. superficial air velocity.
The change in particle volume fractions at the lower and upper parts of the bed are significant at an air velocity of 15 , 20 and 25. However the particle volume fractions at the bottom, and upper part of the bed is more uniform at a dimensionless air velocity of 30 , and it does not vary significantly with further increasing the air velocity. The results show the particle volume fraction is about $36 \%$ in the dense part of the bed and $10 \%$ at the upper part of the bed when the particle transport process becomes stable. Further increase in gas velocity reduces the difference of particle volume fraction at the upper and lower part of the bed.

The results of bubbling, turbulent and transport velocities are used to determine the wide operating range of primary and secondary air velocities in the reactor. The stability of the gas-solid flow in the bed is studied at the constant solid influx of $120 \mathrm{~kg} /\left(\mathrm{m}^{2} \mathrm{~s}\right.$ ) (feed rate $35 \mathrm{~kg} / \mathrm{s}$ ). The feed rate is selected as in the Güssing plant.

Since the process requires the bottom part of the reactor to remain at bubbling fluidization regime, the velocity of the bottom air is fixed to $10 \mathrm{u}_{\mathrm{mf}}$. Separate simulations were run for the increasing primary air while keeping the bottom air flow velocity and the bed material feed rate constant. The particle out flux was monitored with increasing primary gas flow. The result is presented in Fig. 7.

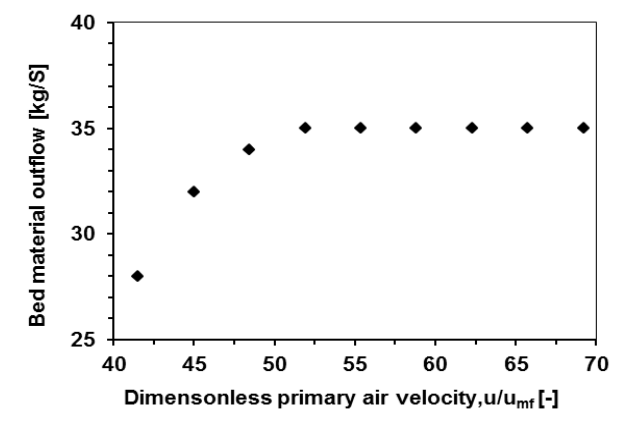

Fig. 7. Bed material outflow vs. air velocity.

At the dimensionless gas velocity less than 48 , the bed material outflow rate is less than the feed rate. When the primary air velocity reached the value of 48 , the bed material inflow and outflow rate is equal. The bed material circulation rate is constant and steady with further increase in primary air velocity. The results show that much more gas feed is needed for the steady transport of particles when the gas feed stream are divided into the bottom air and the primary air.

The bed inventories at increasing primary air velocities are presented in Fig. 8. The results shown in the figure are recorded in 50 seconds of flow time.

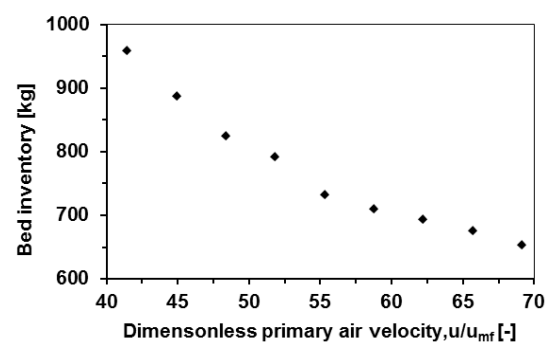

Fig. 8. Bed inventory vs. primary air velocity.

The results indicate that the bed inventory decreases with increasing primary gas velocity. 
A series of simulations were performed to investigate the effect of secondary air on the fluidization regime and particle transport process. In this case, the bottom air as well as primary air feed rate is kept constant in all simulations while increasing the feed rate of secondary air. The velocity of the bottom and primary air are $10 \mathrm{u}_{\mathrm{mf}}$ and $48 \mathrm{u}_{\mathrm{mf}}$ respectively. Simulation results show that the secondary air flow has no significant effect on the particle transport system as long as the feed rate for the bottom and primary air are sufficient.

\section{CONCLUSIONS}

A series of simulation have been performed to identify the various flow regimes in a combustor of a dual fluidized bed gasification system. In addition investigation of the effect of the bottom, primary and secondary air feed on the flow regime and particle transport process was carried out. Three groups of particles have been investigated: Olivine particle, char particle and the mixture of olivine and char particles. The minimum fluidization velocities of char particles, olivine particles and their mixture are $0.06 \mathrm{~m} / \mathrm{s}, 0.06 \mathrm{~m} / \mathrm{s}$ and $0.34 \mathrm{~m} / \mathrm{s}$ respectively with the corresponding transport velocities 2.6 $\mathrm{m} / \mathrm{s}, 2.8 \mathrm{~m} / \mathrm{s}$ and $12 \mathrm{~m} / \mathrm{s}$. The minimum fluidization and transport velocities are found to increase dramatically when two particles of different sizes and densities are mixed.

The average pressure drop across the bed height was determined for the mixture of olivine and char particles at various particle feed rates. The pressure increases and then decreases before becoming stable at a gas velocity about 35 $\mathrm{u}_{\mathrm{mf}}$. At this gas velocity, the solid out-flux also becomes constant. The optimum bottom air velocity is about $10 \mathrm{u}_{\mathrm{mf}}$ and the optimum velocity of the secondary air flow is above $48 \mathrm{u}_{\mathrm{mf}}$. The result shows that the total gas feed rate has to be increased when the feed positions are split as the bottom and primary air instead of single feed position as bottom air. The bed inventory decreases with increasing primary air feed rate. There is no significant effect on the particle transport rate when secondary air is introduced to the bed as long as the bottom and the primary air feed rates are kept sufficient and constant.

\section{NOMENCLATURE}

$$
\begin{aligned}
& \text { Ar }=\text { Archimedes number } \\
& D_{p}=\text { Drag function at the particle location } \\
& d_{p}=\text { particle diameter } \\
& \mathbf{F}=\text { rate of momentum exchange per volume between fluid } \\
& \quad \text { and particle phases } \\
& g=\text { acceleration due to gravity } \\
& N_{p}=\text { numerical particles } \\
& n_{p}=\text { number of numerical particles } \\
& p^{=}=\text {fluid pressure } \\
& p_{s}=\text { positive contact }
\end{aligned}
$$

$\mathrm{Re}=$ Reynolds number

$S_{p \xi}=$ interpolation operator

$\mathbf{u}_{g}=$ fluid velocity

$u_{m f}=$ minimum fluidization velocity

$\mathbf{u}_{p}=$ particle velocity

$U_{t r}=$ transport velocity

$V_{\xi}=$ element volume

$V_{p}=$ particle volume

$\rho_{p}=$ particle density

$\rho_{g}=$ fluid density

$\varepsilon_{c p}=$ particCle volume fraction at close packing limit

$\varepsilon_{g}=$ fluid volume fraction

$\varepsilon_{p}=$ particle volume fraction

$\tau_{g}=$ fluid stress tensor

$\tau_{p}=$ inter-particle normal stress

$\mu=$ gas viscosity

$\phi=$ particle sphericity

$\varepsilon_{c p}=$ particle volume fraction at close packing limit

\section{REFERENCES}

[1] M. Bolhar-Nordenkampf and H. Hofbauer, Gasification Demonstration Plant in Austria, International Slovak Biomass Forum, Bratislava, 2004.

[2] E. Fercher, H. Hofbauer, T. Fleck, R. Rauch, and G. Veronik, "Two years experience with the FICB-gasification process," in Proc. 10th European Conference and Technology Exhibition, Wurzburg, 1998.

[3] H. Hofbauer, R. Rauch, and K. Bosch, "Biomass CHP plant gussing A success story," Expert Meeting on Pyrolysis and Gasification of Biomass and Waste, Strasbourg, France, 2002.

[4] H. Hofbauer, R. Rauch, G. Loeffler, S. Kaiser, E. Fercher, and H. Tremmel, "Six year experience with the FICB-gasification process," in Proc.12th European Conference, and Technology Exhibition on Biomass, Energy, Industry and Climate Protection, Amsterdam, 2002.

[5] H. Hofbauer, G. Veronik, T. Fleck, R. Rauch, "The FICFB gasification process," Developments in Thermochemical Biomass Conversion, 1997, pp. 1016-1025.

[6] S. Kern, C. Pfeifer, and H. Hofbauer, "Gasification of wood in a dual fluidized bed gasifier: Influence of fuel feeding on process performance," Chem. Eng. Sci., 2013, pp. 284-298.

[7] N. Balasubramanian, C. Srinivasakannan, and C. A. Basha, "Transition velocities in the riser of a circulating fluidized bed," Adv. Powder Technol, 2005, vol. 16, no. 3, pp. 247-260.

[8] E. R. Monazam, L. J. Shadle, J. S. Mei, and J. Spenik, "Identification and characteristics of different flow regimes in a circulating fluidized bed," Powder Technol, 2005, vol. 155, no. 1, pp. 17-25.

[9] J. Yerushalmi, D. H. Turner, and A. M. Squires, "The fast fluidized bed," Industrial and Engineering Chemistry Process Design and Development, 1976, vol. 15, no. 1, pp. 47-53. 
[10] L. S. Leung, "Vertical pneumatic conveying: A flow regime diagram and a review of choking versus non-choking systems," Powder Technol, 1980, vol. 25, no. 2, pp. 185-190.

[11] H. Takeuchi, T. Hirama, T. Chiba, J. Biswas, and L. S. Leung, "A quantitative definition and flow regime diagram for fast fluidization," Powder Technol,1986, vol. 47, no. 2, pp. 195-199.

[12] T. Hirama, H. Takeuchi, and T. Chiba, "Regime classification of macroscopic gas - Solid flow in a circulating fluidized bed riser," Powder Technol, 1992, vol. 70, no. 3, pp. 215-222.

[13] J. R. Grace, "Contacting models and behavior classification of gas-solid and other two-phase suspensions," Can. J. Chem. Eng, 1986, vol. 64, pp. 353-363.

[14] H. T. Bi, J. R. Grace, and J. X. Zhu, "Types of choking in vertical pneumatic systems," Int. J. Multiphase Flow, 1993, pp. 1077-1092.

[15] H. T. Bi and J. R. Grace, "Flow regime diagrams for gas-solid fluidization and upward transport," Int. J. Multiphase Flow, 1995, vol 21, no. 6, pp. 1229-1236.

[16] K. Smolders and J. Baeyens, "Hydrodynamic modeling of circulating fluidized beds," Adv. Powder Technol, 1998, vol. 9, no. 1, pp. 17-38.

[17] R. K. Thapa, C. Rautenbach, and B. M. Halvorsen, "Investigation of flow behavior in biomass gasifier using Electrical Capacitance Tomography (ECT) and pressure sensors," in Porc. International Conference on Polygeneration Strategies (ICPS), pp. 97-106.

[18] P. Kaushal, T. Pröll, and H. Hofbauer, "Model for biomass char combustion in the riser of a dual fluidized bed gasification unit: Part II - Model validation and parameter variation," Fuel Process. Technol, 2008, vol. 89, no. 7, pp. 660-666

[19] M. W. Seo, J. H. Goo, S. D. Kim, J. G. Lee, Y. T. Guahk, N. S. Rho, G. H. Koo, D. Y. Lee, W. C. Cho, and B. H. Song, "The transition velocities in a dual circulating fluidized bed reactor with a variation of temperatures," Powder Technol, 2014, pp. 583-591.

[20] A. Kreuzeder, C. Pfeifer, and H. Hofbauer, "Fluid-dynamic investigations in a scaled cold model for a dual fluidized bed biomass steam gasification process: Solid flux measurements and optimization of cyclone," International Journal of Chemical Reactor Engineering 2007.

[21] M. T. Lim, S. Pang, and J. Nijdam, "Investigation of solids circulation in a cold model of a circulating fluidized bed," Powder Technol, 2012, pp. 57-67.

[22] P. Kaushal, T. Pröll, and H. Hofbauer, "Model for biomass char combustion in the riser of a dual fluidized bed gasification unit: Part 1 - Model development and sensitivity analysis," Fuel Process. Technol, 2008, vol. 89, no. 7, pp. 651-659.

[23] P. Kaushal, T. Pröll, and H. Hofbauer, "Model development, and validation: Co-combustion of residual char, gasses and volatile fuels in the fast fluidized combustion chamber of a dual fluidized bed biomass gasifier," Fuel, 2007, pp. 2687-2695.

[24] D. Gidaspow, Multiphase Flow and Fluidization Continuum and Kinetic Theory Description, Academic Press: Boston, 1994.

[25] Y. W. C and Y. Y. H., "Mechanics of fluidization," Chem Eng Prog Symp Ser, 1966, pp. 100-111.

[26] C. Y. W. and Y. N. Yu, "A generalized method for predicting the minimum fluidization velocity," AIChE J, pp. 610-612.

[27] W. C. Yang, A Hand Book of Fluidization and Fluid-Particle System, New York, 2003.
[28] H. T. Bi and J. R. Grace, "Effect of measurement method on the velocities used to demarcate the onset of turbulent fluidization," The Chemical Engineering Journal and the Biochemical Engineering Journal, vol. 57, no. 3, pp. 261-271, 1995.

[29] H. Yerushalmi and N. C. T, "Further studies of the regimes of fluidization," Powder Technol, 1979, pp. 187-205.

[30] K. Smolders and J. Baeyens, "Gas fluidized beds operating at high velocities: A critical review of occurring regimes," Powder Technol, 2001, pp. 269-291.

[31] D. Kunnii and O. Levenspiel, Fluidization Engineering, 2ed, Butterworth-Heinemann: The USA, 1991.

[32] D. M. Snider, "An incompressible three-dimensional multiphase particle-in-cell model for dense particle flows," Journal of Computational Physics, 2001, pp. 523-549.

[33] D. Snider and S. Banerjee, "Heterogeneous gas chemistry in the CPFD Eulerian-Lagrangian numerical scheme (ozone decomposition)," Powder Technol, 2010, pp. 100-106.

[34] M. J. Andrews and P. J. O'Rourke, "The multiphase particle-in-cell (MP-PIC) method for dense particle flow," Int. J. Multiphase Flow 1996, vol. 22, pp. 379-402.

[35] C. Wen, and Y. Yu, "Mechanics of fluidization," Chemical Engineering Progress Symposium Series, 1966, pp. 100-111.

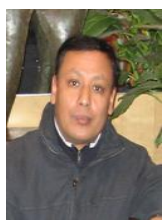

Rajan K. Thapa has got a master degree in mechanical engineering from St. Petersburg State University of Technology and Design, Russia. He has a master degree in process technology and a Ph.D. degree in optimization of flow behaviors in biomass gasification reactor from Telemark University College, Norway. Currently, he is an associated professor in University College of Southeast Norway at Department of Process, Energy and Environmental Technology.

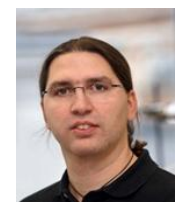

Christoph Pfeifer has got an education in chemical engineering from Vienna University of Technology and carried out his diploma as well his Ph.D. thesis in the field of catalytic tar reforming by primary (in the dual fluidized bed gasification reactor) as well as by secondary measures (downstream fixed bed catalytic reactors). Starting 2005 he was responsible for the development of gasification technologies and the coordination of the pilot plants for gasification (pressurized bubbling fluidized bed gasifier, dual fluidized bed steam gasifier) as well as cold flow modeling of fluidized bed systems for gasification. Currently, he is professor at the University of Natural Resources and Life Sciences, Vienna in the field of Process Technology of Renewable Resources.

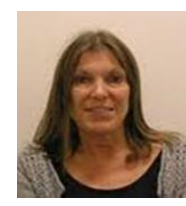

Britt M. Halvorsen has her master in process technology from Telemark University College; the Ph.D. degree is from Norwegian University of Science and Technology and is in the field flow behavior in fluidized bed. Her research work includes both experimental and computational multiphase studies. She has worked within the field of fluidization since 20000. She is employed as professor at University College of Southeast Norway in the field Process Technology. 